\title{
O A PRIORI HISTÓRICO DA DEDUÇÃO TRANSCENDENTAL KANTIANA: UM APORTE FOUCAULTIANO À LEITURA DE DIETER HENRICH
}

\section{THE HISTORICAL A PRIORI OF KANTIAN TRANSCENDENTAL DEDUCTION: A FOUCAULTIAN CONTRIBUTION ON DIETER HENRICH'S READING}

\author{
Caio Souto* \\ Fernando Gimbo**
}

\section{RESUMO}

Este artigo pretende investigar, a partir de um comentário de D. Henrich publicado em 1989 sobre o aspecto jurídico da Dedução transcendental, a relação entre o recurso kantiano à dedução e o problema do jusnaturalismo. Para tanto, propusemo-nos uma estratégia diversa tanto da análise genética quanto da exegese estrutural, detendo-nos sobretudo em questões implícitas que se mostraram inevitáveis à compreensão do princípio admitido pela Dedução transcendental, o qual, por ser, segundo o próprio Kant, apenas um único e mesmo, não pode ser subtraído ao domínio especulativo da razão, donde a necessidade de estender suas implicações à razão prática. Por fim, invocando Foucault, tentamos mostrar que, pelo fato do jusnaturalismo de Kant ser diverso daquele atribuído ao pensamento clássico, o seu argumento não pode ser compreendido segundo os mesmos parâmetros daquele. Por conseguinte, a questão da origem do direito deverá doravante se deslocar da questão sobre a natureza e sua determinação necessária em direção ao sujeito e seu poder normativo reflexivo. PALAVRAS-CHAVE: Dedução transcendental. Juridicidade. Jusnaturalismo. a priori histórico; filosofia política.

\section{ABSTRACT}

This article aims to investigate, based on a comment by D. Henrich published in 1989 on the legal aspect of transcendental deduction, the relationship between the Kantian recourse to deduction and the problem of jusnaturalism. To this end, we have proposed a diferente strategy from both genetic analysis and structural exegesis, focusing mainly on implicit questions that have proved inevitable to the understanding of the principle admitted by transcendental Deduction, which, according to Kant himself, is only one and the same cannot be subtracted from the speculative domain of reason, hence the need to extend its implications to practical reason. Finally, by invoking Foucault, we try to show that, because Kant's jusnaturalism is different from that attributed to classical thought, his argument cannot be understood according to the same parameters as that. Consequently, the question of the origin of law must henceforth shift from the question of nature and its determination toward the subject and its normative reflexive power.

KEYWORDS: Transcendental Deduction. Juridicity. Jusnaturalism. historical a priori; political philosophy

\footnotetext{
* Doutor em Filosofia pela UFSCar com estágio doutoral na Sorbonne-Panthéon Paris-I. Mestre em Filosofia pela UFSCar, Graduado em Filosofia pela UNIFRAN e Graduado em Direito pela PUC-SP. Professor de Filosofia pela UEAP. E-mail: caiosouto@ gmail.com.

** Graduação em Comunicação Social pela Fundação Casper Líbero e Graduação em Filosofia pela USP. Mestrado em filosofia pela UFSCar. Doutorando pela UFSCar. Professor assistente na Universidade Federal do Cariri (UFCA). E-mail: sepefernando@gmail.com.
} 
Há de tudo na Crítica, um tribunal de juiz de paz, um cartório de registros, um cadastro.

(Deleuze, 2006, p. 135).

$\mathrm{Na}$ interpretação de uma obra filosófica, não é apenas a ordem de desenvolvimento explícita que oferece subsídio à leitura e a uma reconstituição lógica, mas também aquilo que, embora de forma implícita, é suscitado necessariamente. É, contudo, leviano buscar numa historicidade extrínseca à obra elementos a auxiliar na recomposição de uma passagem obscura ou considerada como de suma importância. Deve-se antes fazer aparecer a partir da própria obra os elementos que conduzem ao seu exterior. Pois, embora a filosofia resista em sua consistência às mudanças do mundo, mantém com ele uma inevitável reciprocidade pela qual sempre pode ser atualizada. Nesse sentido, nossa proposta não é a de atribuir à filosofia de Kant predicados históricos ou sociológicos que só se lhes aplicam à força de uma violência hermenêutica, mas sim, o que é muito mais modesto, investigar para quais pontos conectivos, sejam eles interiores ou exteriores ao corpo da própria obra, uma dada passagem necessariamente conduz. E nos propomos aqui tomar como objeto o capítulo conhecido como "Dedução transcendental dos conceitos puros do entendimento"1, central à compreensão da Crítica da razão pura, como sugeria já o próprio Kant (A XVI), o que a sucessão de interpretações confirma.

A fim de nos debruçarmos sobre o comentário de Dieter Henrich acerca da Dedução transcendental kantiana em sua relação com o jusnaturalismo, buscando lançarmo-nos a novas considerações (que estão longe de querer esgotar o assunto), iremos nos remeter a apenas três pequenas passagens de Kant. Ademais, não é nosso propósito realizar uma interpretação minuciosa da filosofia kantiana, mas apenas propor um exercício de leitura sobre o caráter do jusnaturalismo na filosofia especulativa de Kant, investigado por Dieter Henrich, dirigindo suas conclusões segundo outro caminho, aquele aberto por Michel Foucault nos livros circunscritos ao período da arqueologia, sobretudo sua Gênese e estrutura da Antropologia de Kant (sua Tese Complementar de doutoramento) e As palavras e as coisas. Em atenção tanto ao comentário de Dieter Henrich quanto à leitura arqueológica de Foucault, não pudemos nos ater a uma leitura estrutural sobre o texto de Kant, modalidade

\footnotetext{
${ }^{1}$ A título de abreviação, doravante a chamaremos simplesmente Dedução, quando não considerarmos a distinção entre as duas edições da Crítica da razão pura, que por sua vez abreviaremos por Crítica; e, quando a considerarmos, acrescentaremos os qualificativos $A$ ou $B$, para designar, respectivamente, a primeira edição de 1781, e a segunda de 1787, seguindo a nomenclatura consagrada ao estudo da obra em questão. Do mesmo modo, sempre que formos citar tal obra, indicaremos entre parênteses as páginas das referidas edições.
} 
importante dos estudos filosóficos mas que, embora traga bons resultados para os que pretendam se ater à obra de um pensador em especial, não tem como mote a exterioridade que subjaz ao pensamento. Também não optamos por realizar uma leitura genética dessas poucas passagens que aqui serão visitadas, o que escaparia aos propósitos de nossa intervenção que pretende, antes, examinar a relação entre a Dedução, com sua pretensão de universalidade, e um momento particular da história cultural e política humana, o do desenvolvimento e da superação do jusnaturalismo clássico.

Por um lado, Dieter Henrich nos mostra como Kant, ao querer legitimar e fundar os conceitos puros do entendimento de modo transcendental (leia-se universal e necessário), possui uma referência histórica, já que as “deduções” eram o procedimento jurídico utilizado durante todo o Sacro Império Romano-Germânico. Michel Foucault, por sua vez, levantará a tese de que, subjacente a todo procedimento filosófico, há um a priori histórico que se correlaciona a certas empiricidades que o pensamento de cada época formaliza e sistematiza a seu modo, não sendo portanto universal e necessário. Essa tese de Foucault permite ir mais além do que D. Henrich, demonstrando que o a priori histórico em que o pensamento crítico de Kant se produz é incomensurável com o a priori histórico em que se tornaria possível o jusnaturalismo clássico. Tal constatação, se levada a cabo, permite mostrar que o “jusnaturalismo" de Kant, já presente na Crítica da razão pura, que terá como pressuposto a figura do sujeito transcendental (figura ausente em seus predecessores), não partilha da mesma configuração epistêmica do jusnaturalismo clássico (aquele de Hobbes, Locke e Rousseau).

\section{A DEDUÇÃO TRANSCENDENTAL}

Situando-se num ponto essencial de concatenação de todo o empreendimento da Crítica, a Dedução é a ocasião em que Kant argumenta pela legitimidade do uso a priori dos conceitos puros (as categorias) em referência a objetos. Mas algo indica que o que está em jogo ali não é apenas a relação entre o entendimento e os objetos dados na sensibilidade, mas também algo que remete à implicação entre os domínios especulativo e prático da razão. Kant diz não poder se servir, quanto à tarefa de esclarecer como pode o entendimento se referir $a$ priori a objetos, de nenhum recurso à experiência. Ao contrário, prossegue, deverá prová-lo segundo uma dedução de direito, a qual ateste ser legítimo tal uso. E na passagem que antecede a Dedução propriamente dita, intitulada "Dos princípios de uma dedução 
transcendental em geral" ( $\$ 13$ da Crítica), evoca a origem do termo dedução na acepção em que passará a utilizá-lo, lançando mão de uma analogia para com os jurisconsultos de sua época, os quais, segundo ele, se referem ao termo para distinguir, num litígio, "a questão de direito (quid juris) da questão de fato (quid facti), e, ao exigir provas de ambas dão o nome de dedução à primeira, que deverá demonstrar o direito ou a legitimidade da pretensão" (KANT, 1989, p. 119; A 84; B 116).

Em sua Dedução, portanto, Kant faz uso de um argumento de juridicidade, emprestado aos procedimentos comuns ao direito de seu tempo, sem deixar, contudo, de produzir-lhe variações. O modo como esse argumento é construído, bem como o que ele pressupõe, permite vislumbrar que a tarefa da Dedução não se restringe à submissão dos dados da intuição às categorias do entendimento, mas se abre a questões que não estão expostas explicitamente na primeira Crítica. Exploraremos a hipótese, tal como indiciada por D. Henrich, mas também por muitos outros comentadores ${ }^{2}$, de haver uma comunicação direta com o domínio prático da razão bem como uma correlação com o jusnaturalismo.

\section{A LEITURA DE DIETER HENRICH DA DEDUÇÃO TRANSCENDENTAL}

Dos intérpretes recentes de Kant, foi de fato Dieter Henrich o primeiro a debruçar-se sobre o caráter especificamente jurídico da Dedução. Seu artigo Kant's notion of a deduction and the methodological background of the First Critique (1989) inicia-se dizendo que o termo dedução utilizado na Crítica possui características comuns ao uso que Kant fará do termo em obras posteriores, notadamente naquelas circunscritas ao domínio prático da razão, defendendo a tese de que haveria um solo ou um fundo metodológico subjacente tanto à Crítica como aos demais textos: "precisamos esclarecer o fundo [background] sobre o qual o raciocínio de Kant nas deduções se desenrola” (HENRICH, 1989, p. 30). O uso do termo dedução teria sido tomado de empréstimo da linguagem do jusnaturalismo e se distinguiria do seu outro uso corrente, o lógico proposicional, segundo o qual se deriva conclusões a partir de premissas anteriormente admitidas como verdadeiras (prova silogística) ${ }^{3}$. No âmbito das contendas jurídicas, a dedução quid juris era o procedimento mediante o qual se verificava a

\footnotetext{
${ }^{2}$ Veja-se, a título de exemplo, além de Henrich (1975, 1989), também Doublet (1989), Bübner (1982), Ishikawa (1995), Kaulbach (1982), Marcos (1994), Pievatolo (1999), Proops (2003) e Seeberg (2006, 2007).

${ }^{3}$ Há comentadores que insistem, porém, na logicidade intrínseca à Dedução, como mais recentemente Caimi (2007). Mas não se trata de dizer que não há uma ordenação lógica em tal raciocínio, e sim que seu procedimento possui um background, como quer D. Henrich, ou um a priori histórico, como Foucault demonstrará, ao qual tal procedimento deve a forma de sua existência.
} 
origem de um determinado direito, independentemente dos fatos. Seria esse o procedimento de que se serviria Kant para provar a origem do direito que o entendimento possui de se referir a objetos: como o procedimento da lógica geral, mero encadeamento proposicional de premissas, não poderia dizer nada acerca da origem de um direito, Kant tivera de buscar outro recurso argumentativo, o qual daria as condições de possibilidade inclusive da aplicabilidade da lógica geral no âmbito formal do pensar, para o que a dedução metafísica havia dado o fio condutor, nos $\S \S 9$ e seguintes da Crítica.

Ao servir-se do termo dedução em seu sentido jurídico, Kant não haveria de se preocupar com a possibilidade de os leitores não entenderem o procedimento, já que era corrente tal uso em sua época, utilizado em todos os estudos referentes à disciplina do direito natural, e mesmo na ordem das disputas jurídicas efetivas. Sempre que se tratava de justificar o uso ou a posse de um determinado direito, isto é, sempre que se buscava legitimar, no domínio fático, o uso ou a posse de um direito, dever-se-ia fazê-lo num âmbito anterior ao prático-factual, em direção à origem primeira desse direito: a esse procedimento, chamava-se dedução. Como sendo a preocupação de Kant, em sua Dedução, a de validar o uso e a posse das categorias do entendimento, teria ele buscado fazê-lo dirigindo-se à origem primeira do que concebia como o direito legítimo de que são dotadas as categorias, não bastando a tal argumentação invocar o mero fato de que elas realmente se encontram alojadas a priori no sujeito transcendental (como mostraria a lógica geral) e que seriam portanto condições de todo o conhecimento possível. Pois, a exemplo do que ocorria quando da distinção entre uma exposição metafísica e uma exposição transcendental no domínio da sensibilidade, haveria uma diferença essencial entre constatar a existência ou mesmo o surgimento de um conceito e aferir a sua necessidade. Ocorre que, quanto ao entendimento, a prova de tal necessidade não se poderia dar sem recorrência a um argumento de legitimidade. Quanto a isso, Kant teria meditado por longos anos antes de optar por recorrer ao procedimento dos jurisconsultos para retroagir até a origem natural do direito. No caso de Kant, referir-se-ia às categorias de que o entendimento humano é dotado. Além disso, uma dedução jurídica costumava restringir também o âmbito da extensão do direito o qual ela legitimava. Kant quereria provar, também, a limitação das ditas categorias, que não poderiam ultrapassar o domínio da experiência, justificando seu argumento de que tal transcendência do uso do entendimento faria a razão recair numa ilusão, o que significaria ser esse o resultado de um uso ilegítimo do entendimento. 
Porém, aos leitores atuais, não familiarizados com o sentido jurídico comum ao século XVIII do termo "dedução", poderia parecer que Kant, no início do $\S 13$ da Crítica, apenas se serviria do direito para dizer a respeito de suas premissas que elas teriam um teor jurídico, mantendo porém, no decorrer do argumento, uma estrutura lógica comum. E é contra esse modo de leitura que Henrich quis se posicionar, já que tal proposta interpretativa perderia a característica principal desse método dedutivo empregado por Kant e que é coerente ou extensível ao uso prático da razão. E para expor as características desse método, Henrich fez recurso à História, para explicar como se dava esse procedimento no plano das disputas jurídicas efetivas. Com isso, priorizou não apenas características que seriam externas à Dedução, mas fez notar o que se perde ao se priorizar, em contrapartida, apenas o critério lógico intrínseco a um sistema filosófico. É nesse sentido que gostaríamos de prosseguir pelo caminho aberto por Henrich ao coração da Crítica, recuperando a sua leitura do $\S 13$ para extrair dele, contudo, consequências um pouco diferentes.

\section{O CARÁTER HISTÓRICO DA DEDUÇÃO TRANSCENDENTAL}

Entre o final da Idade Média e os primeiros anos do século XIX, sempre que se questionava se era legítimo ou não o domínio sobre um determinado território, ou a posse de alguma coisa, levava-se ao governo do Sacro Império Romano-Germânico (o qual só seria dissolvido em 1806 por Napoleão) uma peça acusatória, que seria confrontada com uma peça defensiva. A fim de dilucidar tais litígios, havia à disposição dos governantes, encarregados do seu julgamento, deduções que eram escritas por pessoas dotadas de um saber técnico específico, os jurisconsultos, investidos numa promissora profissão, dada a sua dificuldade e importância. Kant conhecia bem tais procedimentos, assim como o seu vocabulário, uma vez que ele mesmo o utilizara em disputas jurídicas pessoais. Ademais, certamente sabia que o público a quem seus textos filosóficos eram dirigidos também conhecia essa modalidade discursiva. O próprio texto da Dedução, além de ser introduzido ( $\$ 13$ ) por uma explícita analogia ao gênero, prossegue, nas duas edições, em absoluta conformidade com seu procedimento. Ao final, seguindo o modelo jurídico de exposição, apresenta ainda um breve resumo do que havia ali exposto, recordando os principais aspectos com relação à legitimidade do uso de um determinado direito, no caso, o da validade objetiva das categorias do entendimento. 
Numa dedução jurídica, o que se queria provar era a origem de um direito, em geral quanto a transmissões de bens e de posses entre gerações, seja por sucessão, seja por disputas militares, as quais igualmente deveriam ser reconhecidas como legítimas por juízes e governantes. Quanto à origem absolutamente primeira desses direitos, porém, uma dedução nada tinha a dizer, dando como presumido um princípio primeiro, o qual se ancorava no jusnaturalismo clássico, segundo o qual os direitos do homem provêm da natureza, sendo originários. Na Dedução transcendental, parafraseando D. Henrich, não se trataria meramente de atestar a existência de um direito. Isso seria de todo impossível, uma vez que as categorias são originárias ao sujeito e não podem pressupor nada que lhes seja anterior, ou que seja anterior ao próprio sujeito. Por isso, Kant deveria esgotar a investigação originária de sua Dedução no próprio sujeito de direitos como fundamento, dotado das categorias que lhe são intrínsecas, tomando por recurso uma busca em escala ascendente até culminar no seu princípio fundamental, para além do domínio fático. Do mesmo modo, as deduções jurídicas jamais poderiam encontrar no campo dos fatos um fundamento último das sucessões, numa escala ascendente ao infinito, pois ou chegariam num momento histórico irreconstituível ou teriam de alçar voo rumo a uma dimensão mítica ou pré-histórica: "O Direito Natural que Kant utiliza como seu paradigma reconhece uma aquisição originária. As condições de sua legitimidade podem ser determinadas antes de qualquer sistema jurídico particular." (HENRICH, 1989, p. 36). Tal originariedade, então considerada como de direito, suprimiria as deficiências de que, no plano dos fatos, não se poderia escapar.

Não se pode saber quando Kant tenha decidido expor seu método de justificação filosófica na terminologia das deduções jurídicas. O que Henrich dá como certo é que sua decisão se estendeu para além da Dedução e que, embora se distinga por seu teor e método do restante da Crítica, marcaria um paradigma metodológico que afetaria todo o restante do texto, bem como as obras posteriores do autor. A Crítica não faria mero empréstimo de um procedimento jurídico; ao contrário, estaria toda ela construída da mesma maneira como eram decididos os conflitos jurídicos à época. Uma disputa jurídica tinha lugar quando alguém reivindicava um direito a um oponente: ora, isso teria acontecido quando os céticos (para Kant, espécies de bárbaros e nômades) desafiaram a razão a poder ter alguma forma de conhecimento a priori. Tal disputa necessitaria ser levada a um tribunal, no qual se averiguasse a origem desse direito. E somente uma dedução poderia oferecer o método seguro para tanto, uma vez que era o procedimento por excelência de inquirição pela Ursprung de um direito. 
Prosseguindo, e agora somos nós que conduzimos a análise, o capítulo III da Analítica dos princípios iria ainda mais longe no paralelismo com os resultados de uma dedução jusnaturalista. Agora o entendimento puro se tornaria um país, uma ilha, "a que a própria natureza impõe leis imutáveis. É a terra da verdade" (KANT, 1989, p. 255; A 235; B 294295). O direito natural do entendimento de aplicar suas categorias a objetos teria encontrado seu porto seguro, para além do qual a lei civil que ele deveria impor-se a si mesmo não deveria deixá-lo ir. E se ele buscasse transpor tal limite, o que seria no entanto de sua natureza fazê-1o ${ }^{4}$, adentraria domínios alheios ao seu, os quais ele não possuiria legitimamente. Observa-se que noções próprias ao jusnaturalismo, tais como as de "estado de natureza" e de "estado civil", ajustam-se plenamente à filosofia especulativa de Kant. A razão teria encontrado um limite à sua propensão natural, uma limitação que lhe seria imposta a partir de si mesma, a qual instauraria um estado civil especulativo, restringindo a sua liberdade de conhecer o que quer que seja, mas para garantir um melhor e mais adequado uso de sua liberdade, uma vez que seria enfim livre para se exercer plenamente no domínio dos fins últimos, no uso moral da razão prática. Tendo assim respondido aos céticos e deles se resguardado no porto seguro do entendimento, restaria ainda responder aos dogmáticos.

Retomando mais uma vez Henrich, a Dialética transcendental seria a ocasião em que se daria a palavra àqueles que acreditam que a razão pode estender os limites de seu domínio para além do "país do entendimento puro". Mas o que o procedimento dedutivo (na acepção jusnaturalista) então encontraria é uma total impossibilidade de se estabelecer a legitimidade dessa pretensão. Nos casos das disputas concretas, quando isso ocorria (a prova da impossibilidade da origem de um direito), a parte envolvida no conflito deveria declinar de seu requerimento, o que não levava necessariamente a uma vitória da outra parte:

\footnotetext{
Numa tal situação, em que as reivindicações conflitantes não podem ser resolvidas no tribunal em favor de uma das partes, estas ameaçam envolver-se numa luta sem fim, que iria destruir a paz e resultar em uma guerra dentro da própria razão. A decisão do tribunal da razão numa tal situação consiste na ordem de manter a paz. (HENRICH, 1989, p. 38).
}

A razão recuaria de sua pretensão em avançar os limites da experiência, e se restringiria ao território o qual estaria segura de possuir legitimamente. Constranger-se-ia a

\footnotetext{
${ }^{4}$ Já se concebia, desde o prefácio à primeira edição da Crítica (A VII), a natureza da razão como sendo a de se precipitar em ilusões, o que ocorreria quando, seguindo seu "singular destino", ela perdia o chão e abstraía de todo o conhecimento empírico, buscando impor a coisas que escapam à experiência conceitos que não podem se referir senão à experiência.
} 
um pacto civil no qual sua pretensão natural ao conhecimento ficaria situada tão somente no registro especulativo. Porém, conforme a máxima "se uma disputa sobre o acerto de um uso não possa ser resolvido, o uso continua com o possuidor", uma vez que a razão continua em posse de suas ideias (dada a indemonstrabilidade do contrário, ainda que ela também não possa provar a legitimidade desse uso), o caminho para uma filosofia "puramente prática" permaneceria em aberto. E se a razão deveria experimentar um interesse legítimo pela coisaem-si, não o deveria fazer no campo especulativo, devendo buscá-lo num nível superior, o dos seus fins últimos, tarefa que já estaria anunciada pelo fundo metodológico da Dedução, a legitimar e restringir o uso das categorias do entendimento e, consequentemente, do que restaria como próprio à razão pensar, independentemente dos limites especulativos do conhecimento. A questão da Crítica da razão pura, segundo Henrich, centrada na Dedução, seria portanto a de uma dedução filosófica dos direitos adquiridos em filosofia, a passagem de um "estado de natureza filosófico" a um "estado civil filosófico", à maneira como alguns jusnaturalistas entendiam tais termos aplicados ao estudo da política e do direito, argumentando que a humanidade, quando chegada ao estado civil, enfim efetivaria os seus fins últimos. A origem da legitimidade do uso das categorias aos dados da experiência é comum à origem dos direitos civis inalienáveis, uma mesma e única Ursprung.

Ocorre, porém, que o fato de Henrich não propor nenhuma distinção entre o jusnaturalismo clássico e o de Kant impossibilita que percebamos em que a Dedução kantiana difere ontologicamente das deduções jurídicas do seu século, como podemos afirmar após a leitura de As palavras e as coisas. Ademais, a Dedução é correlata a uma modificação que se passa também quanto às implicações políticas com as quais se conecta. Nesse sentido, antes de apresentarmos as implicações foucaultianas à leitura de D. Henrich, retomemos alguns pontos importantes do pensamento jusnaturalista clássico, para elucidarmos o que estamos a dizer quanto à diferença introduzida pelo jusnaturalismo de Kant.

\section{O JUSNATURALISMO CLÁSSICO}

Como ensina um historiador do direito, Michel Villey, durante a Baixa Idade Média, os jurisconsultos possuíam uma ideia de lógica que nada se aparenta com um sistema dedutivo (no sentido corrente) articulado segundo regras todas elas reportadas a um princípio normativo. Imperava um modelo que conjugava a dialética ao Órganon aristotélico e cuja operacionalidade era fornecida pela retórica: perseguiam-se valores, e não leis. E não é 
nenhum exagero dizer que uma lógica como a de Abelardo deva ser compreendida correlatamente ao modelo de resolução das controvérsias jurídicas: os juízes de então confrontavam as pretensões entre os adversários opondo-as dialeticamente, servindo-se de um procedimento que deveria levar em conta numerosos elementos, os quais eram sopesados numa avaliação que exigia um nível de cultura sem dúvida elevado (VILLEY, 2005, p. 425436).

Quando os estudos escaparam ao domínio da alta Igreja, criou-se uma elite culta de outra ordem, formada, principalmente, pelo baixo clero, por burgueses enriquecidos e por nobres libertos de sua atividade militar. Estes, preocupados em contrapor-se ao poder teológico-político do papado e dos imperadores, foram buscar as fontes para uma revitalização dos ideais românicos, pondo à parte as doutrinas acumuladas pelas escolas medievais. Com a irrigação que a leitura dos latinos trouxe, criou-se um solo apto à formulação de teorias que buscavam ao direito e ao Estado uma unificação. No plano das práticas, o Estado absolutista nasceu como reação ao modo plural como a sociedade medieval se organizava; no plano teórico, correlatamente, tentou-se pensar um princípio políticojurídico unificador. A obra de Grotius pôde nascer, definindo "uma fonte de conhecimento jurídico que não provenha da revelação divina mas subsista, pelo contrário, por sua própria 'natureza' e evite assim toda mácula e toda falsificação" (CASSIRER, 1992, p. 325).

A obra de Maquiavel encontrou aí um ambiente propício para crescer e fecundar. E foi à custa de uma reconfiguração acerca do pensamento sobre o que fosse o homem e de onde viriam seus direitos que a autonomia política do Estado foi pensada. Em todo caso, Maquiavel proporcionou, contra o pensamento medieval que concebia como múltiplos os princípios que definiam cada Estado, um modelo de compreensão política segundo o qual não se deveria recorrer a nada exterior ao Estado para defini-lo, nem a elementos que lhe fossem internos (como o conjunto de seus membros) nem externos (como uma ordem divina). E exigia um agente regulador que mantivesse a coesão estatal: trata-se da ideia de "razão de Estado" que surge no limite entre a Idade Média e o Renascimento (FOUCAULT, 2008, p. 341-417). Durante os séculos seguintes, assistir-se-á a uma contraposição ante a herança teórica renascentista, cujo princípio da "razão de Estado" sofrerá algumas modificações. O "maquiavelismo", que passará a ser empregado em sentido depreciativo, pôde então desempenhar um papel importante, ainda que negativamente, pois foi, em grande medida, como reação à teoria do Estado sem limites (que concebia um príncipe como acima dos 
limites morais, religiosos e também jurídicos) que os jusnaturalistas dos séculos XVII e XVIII articularam as suas ideias (BOBBIO, 1984, p. 13-15).

Foi paralelamente a esse campo político, e sobre esse fundo teórico, que Hobbes, uns dos primeiros grandes teóricos do direito natural moderno, estabeleceu um critério científico para a compreensão do que então se denominavam as ciências morais ${ }^{5}$. Ao contrário da doutrina aristotélico-medieval, que empregava a dialética e a retórica na compreensão e na resolução das querelas, bem como um procedimento indutivo-comparativo para se definir o que seria a natureza humana, Hobbes propôs um método demonstrativo circunscrito a um sistema de normas concatenadas. Trata-se de um modo inteiramente diverso daquele consistente em meramente interpretar ações dadas conforme a elas mesmas, já que doravante se quererá fundar a legitimidade de tais ações numa ordem racional, à maneira como também começaram a fazer os cientistas da natureza. Seguindo esse intuito empirista, Hobbes viu-se impelido a fazer tabula rasa de todas as teorias que lhe antecederam e a lançar-se à empresa de investigar demonstrativamente o que seria o próprio homem segundo uma identificação direta entre este e a natureza. Seu famoso modelo constitui duas situações hipotéticas as quais seriam mutuamente excludentes: o estado de natureza, em que o homem agiria de modo não associado, sendo guiado por suas paixões, instintos e interesses; o estado civil em que ele se associaria abdicando de sua liberdade natural. A passagem entre um estado e outro se daria por intermédio de um pacto. O que caracteriza essa teoria é o fato de o princípio de legitimação do chamado estado civil ser o consenso, portanto um ato no qual cada indivíduo reconhece a necessidade de alienar a sua liberdade, porque, se a seguissem todos, a sociedade não escaparia a uma luta perpétua. Em todo caso, trata-se o estado de natureza de uma demonstração especulativa: Hobbes despe a natureza de todo revestimento teológico, admitindo ao poder político uma aquisição originária do direito à liberdade.

Locke, também perseguindo o ideal de uma ciência demonstrativa da moral, compartilha com Hobbes a recusa em se buscar, como fazia o aristotelismo, o que fosse a natureza humana segundo uma pesquisa empírica comparativa entre todas as sociedades, investigando-a antes segundo uma dedução demonstrativa. Porém, à diferença de Hobbes, Locke concebe a passagem entre o estado de natureza e o estado civil não como uma absoluta

\footnotetext{
${ }^{5}$ Quanto ao jusnaturalismo de Hobbes, segue-se um debate; ver Cassirer (1992, p. 337-345), Schmitt (2008), Strauss (1973, 2014), Lebrun (2006a, 2006b) e Moura (2001).
} 
alienação da liberdade, mas, bem ao contrário, como uma plena garantia desse direito natural ${ }^{6}$. Trata-se de uma modificação considerável na doutrina do direito natural, a qual veremos conservada mutatis mutandis em Kant. A teoria do pacto em Locke faz derivá-lo da vontade comum a todos os homens de conservar o seu direito natural à liberdade e, correlata a esta, à propriedade, estabelecida desde a origem no contato e no trabalho mantido com a natureza. É nesse cenário filosófico - segundo um princípio comum de distinção entre o que seria um "estado de natureza" e um "estado civil" - que Kant desenvolverá sua filosofia crítica. E se aparentemente conserva muitos de seus aspectos, Foucault demonstrará que seu jusnaturalismo difere por natureza do jusnaturalismo da Idade Clássica, por uma questão fundamental: o princípio supremo que garante ao homem a originariedade de seus direitos (seja no âmbito da liberdade prática, seja no da validade objetiva do entendimento) não é buscado numa ordem comum ao homem e ao mundo que lhe é exterior. Tal mudança deverá bastar para que não possamos identificar Kant com os demais jusfilósofos que lhe antecederam $^{7}$.

\section{KANT E O NASCIMENTO DO JUSNATURALISMO MODERNO}

Entre a publicação das duas edições da Crítica, mais precisamente em 1785, Kant publica sua Fundamentação da metafísica dos $\operatorname{costumes}^{8}$, na qual dizia algo que aumenta nosso interesse pela relação entre a razão especulativa e a razão prática, ambas reportadas a um mesmo e único princípio:

[...] para que a Crítica de uma razão pura prática possa ser acabada, que se possa demonstrar simultaneamente a sua unidade com a razão especulativa num princípio comum; pois no fim de contas trata-se sempre de uma só e mesma razão, que só na aplicação se deve diferençar. (KANT, 1974, p. 200).

Ora, não é portanto sem interesse que propomos buscar, na obra moral e política de Kant, as suas diferenças para com o jusnaturalismo então vigorante, para então retornarmos ao exame da Dedução, que, como queremos mostrar, não pode de modo algum ser identificada com os procedimentos jurídicos operados segundo as doutrinas classicistas do direito natural.

\footnotetext{
${ }^{6}$ Quanto ao jusnaturalismo de Hobbes, segue-se um debate ver Cassirer (1992, p. 337-345), Schmitt (2008), Strauss (1973, 2014), Lebrun (2006a, 2006b) e Moura (2001).

${ }_{7}$ Tal tese destoa da interpretação comum do jusnaturalismo, que costuma identificar apenas na filosofia da História de Hegel uma ruptura radical para com o jusnaturalismo clássico.

${ }^{8}$ Doravante simplesmente Fundamentação.
} 
Na Fundamentação, Kant se serve dos conceitos tradicionais de moralidade e legalidade para definir uma distinção puramente formal, segundo a qual o que determina se uma ação é moral encontra-se no livre cumprir racional do dever. Dessa forma, opera-se uma distinção entre o que é interno ao sujeito e o que lhe é externo, devendo a moral indagar pelo animus (Gemüt) que determinou a ação, e não pelo seu mero resultado. Segundo essa concepção, o direito, e consequentemente o Estado, que já havia voltado a ter nessa época a lei como principal expressão (diferentemente do período medieval), deveria limitar-se em julgar as ações externamente, reconhecendo da esfera íntima da moral o julgamento das intenções das ações individuais. A consciência do sujeito passava a não se submeter de direito ao poder estatal.

Kant propõe uma limitação ao Estado quanto à sua atuação perante a moralidade de nossas ações, fundando no próprio sujeito - considerado não empiricamente, mas sim tal como ele pode ser pensado a priori (independentemente da experiência), e tal como ele deve ser num âmbito transcendental (necessário e universal) - como originário em si mesmo, sem identificação com uma natureza, que em todo caso não pode ser conhecida tal como seja em si mesma, a liberdade que deve guiar as suas ações. Ora, seguindo essa liberdade originária, não mais substancial como no pensamento dogmático, mas que deve ser sempre reportada a um preceito moral (“age como se..."), o sujeito passa a dever encontrar em si mesmo uma autorregulação, num esforço de adequação a uma lei que ele mesmo se põe no exercício da razão.

No pensamento clássico, aquele dos séculos XVII e XVIII, tratava-se de identificar os direitos do homem com a natureza, o que se buscava fazer de um modo demonstrativo, seja entre os empiristas, seja ainda entre filósofos dogmáticos. As diferenças que opõem Hobbes a Locke, por exemplo, são encontradas no plano do desenvolvimento intrínseco às suas teorias; todavia, pode-se encontrar uma similaridade em ambas buscarem à natureza o princípio que determina a origem dos direitos humanos. E ainda que um a tenha referido a uma liberdade selvagem que deveria ser alienada absolutamente para que se instaurasse o estado civil, e o outro a tenha reportado a uma liberdade ameaçada pela barbárie e que se deveria garantir, invertendo o sentido do pacto, trata-se de um procedimento equivalente de dedução jurídica de tais direitos. O que também se encontra em Rousseau, que se lhes oporá um ainda outro modelo de contrato, em que a discórdia, agora compreendida como gerada pela própria sociedade civil, e que deveria ser estancada pela criação pactual de um Estado governado pela vontade geral, ainda deduz o direito à liberdade humana como natural, sem realizar qualquer 
exame acerca de sua universalidade e necessidade. É mesmo com Kant que enfim se precipita uma separação entre o que seria propriamente natural ao homem e o que the é devido de direito segundo uma dedução transcendental. Não há mais, como entre os jusnaturalistas clássicos, uma perfeita identificação entre as leis da necessidade (aquelas atribuídas à natureza) e as leis da liberdade (aquelas deduzidas pelo dever moral).

De modo que, ao introduzirmos a filosofia política da Idade Clássica ao interior das disputas metafísicas que comumente se reconstituem como sendo o problema cuja Crítica teria vindo solucionar, acreditamos não fazer senão mostrar ser essa talvez ainda mais complexa do que apenas uma discussão de teor lógico-especulativo. Pois não é apenas a vertente metafísica do pensamento de Leibniz e Wolff, de um lado, e de Hume, Locke e Berkeley, de outro, que figura como adversária à Crítica, como também a vertente jurídicopolítica da teoria do direito natural, a qual esgotava a investigação pela origem dos direitos humanos numa identificação pré-crítica com as leis da natureza. Ademais, não parece ser gratuito que Kant acrescente à palavra "dedução", admitidamente recuperada do repertório jurídico, o qualificativo transcendental, como a mostrar que a sua dedução investigaria um domínio universal e necessário dos direitos, e não apenas sua origem comum ou natural.

No que respeita enfim ao que caracteriza propriamente o jusnaturalismo clássico, isto é, uma respectiva teoria do "contrato social", perguntemo-nos o que se pode concluir, uma vez admitido que Kant não identifica absolutamente a origem dos direitos humanos com uma natureza, mas busca deduzi-los independentemente de qualquer recurso que seja extrínseco ao sujeito. Reconhecemos através da filosofia crítica de Kant que esse princípio, o qual é dado originariamente no sujeito, pode diferir em suas características, quando concernente seja à razão pura, seja à razão prática. Quanto à primeira, resume-se nas categorias do entendimento que possuem o direito originário de conhecer objetos, conforme à Dedução; e se, em seu estado de natureza, a falta de limites pode comprometê-las, uma vez que elas incorrem em domínios que não lhes oferecerem nenhum conhecimento, o estado civil vem lhes garantir a total segurança para atuar sobre territórios os quais possuem legitimamente. Quanto à razão prática, por sua vez, igualmente o pacto que instaura o estado civil não aliena a liberdade derivada da autonomia do sujeito, mas sim a conserva e a fortalece, ampliando suas possibilidades, guardando ressonâncias para com o liberalismo de Locke.

Aquilo que todavia distingue Kant de Locke no que respeita à teoria política é coerente à sua distinção no plano especulativo. Para o empirista que recusa as ideias inatas, a liberdade inalienável concernente ao homem em sua identificação com a natureza, uma vez que ele não 
é senão mera organização viva de formas naturais, não pode gozar de nada que lhe seja absolutamente universal e necessário. A filosofia crítica se oporá às duas consequências disso: quanto à consequência política, não conceberá o contrato como um cálculo interessado em que os indivíduos, por motivos de utilidade, resolvem instaurar um estado civil para assim assegurar o direito natural à liberdade, uma vez que é a obediência a uma lei moral, fundada na autonomia do sujeito, que propulsiona a criação do estado civil. Quanto finalmente à razão especulativa, uma vez provado que o sujeito possui tanto formas a priori na intuição quanto conceitos a priori no entendimento, será forçoso concluir que o sujeito não pode aliená-los, mas que deve restringir a atuação destes últimos a um âmbito específico, o qual lhe é dado legitimamente possuir, o que se dá em virtude da instauração de uma ordem civil no registro puro da razão. Prova esta que se exaure num mesmo e único princípio. E como não se quer lançar mão a um argumento plenamente naturalista, pois se deve investigar uma origem primeira num âmbito puro, universal e necessário, há que se admitir que o homem difere qualitativamente da ordem natural.

\section{CONCLUSÕES FOUCAULTIANAS}

Dieter Henrich, em sua profunda e elucidativa análise da Dedução transcendental, conseguiu mostrar em quais procedimentos jurídicos de sua época ela se baseava, bem como também foi capaz de apontar para a inserção de tais procedimentos na obra de Kant: trata-se a Dedução transcendental, no fundo, de um ponto de articulação da filosofia moral e política no coração de sua teoria da razão pura. Porém, essa abordagem possui um limite. Ela não observa em que sentido já se modificara o solo (Foucault poderia dizer aqui o "a priori" histórico, ou para utilizar o termo do próprio Henrich, o background) sobre o qual se assentava esse procedimento ao mesmo tempo jurídico e filosófico. Assim, não permite perceber em que ponto justamente a argumentação de Kant também é efeito de uma profunda modificação nesses procedimentos de dedução jurídica que tinham lugar em seu período histórico e que são assemelhados à sua Dedução filosófica. É por isso que um aporte foucaultiano a essa leitura de Henrich permite torná-la ainda mais consistente, embora também desloque o seu sentido num ponto essencial.

Ora, no seu procedimento dedutivo, Kant introduz a "unidade originariamente sintética da apercepção" como uma qualidade supracategorial, mas que não pode ser apressadamente identificada com uma unidade natural ou divina. A Dedução B, a qual segue 
um critério lógico mais evidente, apresenta em seu início ( $§$ 15) o princípio cuja argumentação seguinte virá justificar. Trata-se da unidade do eu no Eu penso, a qual deverá dar unidade às representações que advêm dos objetos empíricos aos eus empíricos difusos. Nota-se aqui, contudo, uma diferença de natureza entre o "Cogito kantiano" e o sujeito tal como era apresentado seja pelos empiristas seja pelos racionalistas dogmáticos, para os quais se tratava de identificar por demonstração uma identidade entre aquilo que tornava possível o eu (seja como substância pensante, seja como hábito) e uma ordem natural. Doravante, o Cogito será concebido como um princípio em tudo diverso do que lhe é exterior, que não corresponde senão às características intrínsecas ao sujeito ante suas representações tais como elas consistem em si mesmas. Nesse sentido, Kant propõe um princípio de unidade ao pensamento cognitivo sem o qual não haveria conhecimento, mas o encontra em si mesmo, no próprio sujeito transcendental, como lei universal e necessária. Eis aqui uma conclusão que não poderia ser tirada meramente dos procedimentos jurídicos até então ocorridos, pois, ao assumir de antemão uma unidade originária do sujeito, Kant está inserindo uma nova figura até então ausente do jusnaturalismo clássico: o sujeito, não mais a mera natureza.

Sabemos que, ao narrar a passagem entre a episteme clássica e a episteme moderna, Foucault em As palavras e as coisas abordava justamente a obra de Kant, que lhe fornecia o melhor exemplo do limite entre essas duas configurações do pensamento ocidental. Na esfera jurídica, observamos que o jusnaturalismo clássico não concedia nenhuma autonomia ao sujeito, o qual era pensado sempre em referência à ordem do mundo. Mas na modernidade é o sujeito quem deverá dar a si mesmo a sua lei, ainda que tal não contradiga que haja uma correspondência originária com uma natureza ou com uma razão divina (esse argumento é simplesmente suspenso pela Dialética transcendental). Ocorre que, em Kant, a ordem transcendental do sujeito se organiza de um modo autônomo, ainda que no caso jurídicolegalista essa autonomia se relativize, uma vez que o sujeito deve sempre reportar ao Estado como representante concreto da coletividade. E essa autonomia é também aferida especulativamente na consciência que $E u$ tenho de que devo acompanhar todas as minhas representações, impondo-lhes uma unidade sem a qual não produzo nenhum conhecimento. E suas implicações imediatamente jurídico-políticos ostentam uma precipitação com relação ao jusnaturalismo que conduzem a outras consequências pragmáticas, bem como reportam a uma configuração na ordem do saber europeu que já não se coaduna com o pensamento clássico. $\mathrm{O}$ termo originariedade em Kant ganha outro sentido, para além do qual não há mais nenhuma sobredeterminação: o princípio primeiro é, portanto, uma reflexão. 
O que, no procedimento da Dedução, demonstra a relação com o domínio da razão prática é, sem dúvida, a recorrência a um princípio primeiro incondicionado, buscado à reflexão, o qual, no caso puro, atribuiria legitimidade às pretensões do entendimento ante a receptividade e indicaria que, onde sua atividade é ilegítima, há um caminho aberto para a razão em seu uso moral. Pois é Kant mesmo quem assemelha o caráter restritivo da Crítica ao de uma polícia, dizendo que, ao impedir que a razão especulativa avançasse por zonas ilegítimas, para além da experiência, deixaria livre o caminho para que a razão prática então se exercesse sem esteios, em seu uso necessário aos fins últimos da ação humana, em que a razão deveria se estender para além do domínio da sensibilidade, "não carecendo para tal, aliás, de qualquer ajuda da razão especulativa, mas tendo de assegurar-se contra a reação desta, para não entrar em contradição consigo mesma" (B XXV) ${ }^{9}$.

Sendo assim, talvez se pudesse acrescentar às análises histórico-críticas de Henrich que esse problema central à Crítica - que o mencionado comentador compreende como sendo o de uma incompossibilidade entre reflexão (implícita) e investigação (explícita) corresponde a uma mais profunda modificação no pensamento ocidental. Como dirá Foucault, a obra de Kant permite compreender uma mudança epistêmica no quadro do pensamento, isto é, uma mudança no seu a priori histórico. É que quando o fundamento da síntese possível entre as representações passa a ser reportado a um sujeito, considerado como tal segundo uma reflexividade que o torna qualitativamente diferente da natureza, tem-se a instauração de um paradigma absolutamente diverso daquele até então seguido pelos jusnaturalistas. E se Henrich notou haver uma discrepância na ordem da filosofia crítica, ainda que ilusória, entre uma argumentação "frouxa" (empírica) e uma argumentação "elevada sobre a sistematicidade" (transcendental) ${ }^{10}$, é porque são esses justamente os traços principais que distinguirão essa filosofia das que floresceram entre os séculos XVII e XVIII. Por outro lado, e fazendo jus à relevância dessa interpretação de D. Henrich, ela também permite melhor compreender em que sentido é necessário lançar mão de outros métodos de análise de textos filosóficos, para além da leitura estrutural e da análise genética. Isso por si só já é uma contribuição inestimável para os historiadores da filosofia.

\footnotetext{
${ }^{9}$ Kant (1989, p. 25).

${ }^{10}$ Henrich (1989, p. 46).
} 


\section{REFERÊNCIAS}

BOBBIO, N. Direito e estado no pensamento de Emanuel Kant. Brasília: UnB, 1984.

BÜBNER, R. Selbstbezüglichkeit als Struktur transzendentaler Argumente. In: Böhler, D; Kuhlmann, W (Hrsg). Kommunikation und Reflexion. Zur Diskussion der

Transzendentalpragmatik. Antowrten auf Karl-Otto Apel. Frankfurt: Suhrkamp, 1982.

CAIMI, M. Leçons sur Kant: la déduction transcendentale dans la deuxième édition de la Critique de la raison pure. Paris: Publications de la Sorbonne, 2007.

CASSIRER, E. A filosofia do iluminismo. Tradução Álvaro Cabral. Campinas: Editora da Unicamp, 1992.

DELEUZE, G. Diferença e repetição. Tradução Luiz Orlandi e Roberto Machado. Rio de Janeiro: Graal, 2006.

DOUBLET, D. R. Die Vernunft als Rechtsinstanz. Kritik der reinen Vernunft als Reflexionsprozeß der Vernunft. Padeborn \& Oslo: Verlag Ferdinand Schöningh \& Solum Forlag A/S. 1989.

FOUCAULT, M. As palavras e as coisas. Tradução Salma Tannus Muchail. São Paulo: Martins Fontes, 2002.

FOUCAULT, M. Segurança, território, população. Curso no Collège de France. Tradução Eduardo Brandão. São Paulo: Martins Fontes, 2008.

GOLDSCHMIDT, V. Tempo histórico e tempo lógico na interpretação dos sistemas Filosóficos. In: GOLDSCHMIDT, V. A religião de Platão. São Paulo: Difusão Europeia do Livro, 1963, p. 139-147.

HENRICH, D. Die Deduktion des Sittengesetztes". In: Schwan, A (Hrg). Denken im Schaten des Nihilismus. Festschrift für Wilhelm Weischedel zum 70. Geburststag. Darmstadt: WBG, 1975. Bes. S. 76-84.

HENRICH, D. Kant's notion of a deduction and the methodological background of the first Critique. In: FÖRSTER, E. (ed.). Kant's Transcendental Deductions. Stanford: Stanford University Press, 1989.

ISHIKAWA, F. Zum Gerichtshof-Modell der Kategorien-Deduktion. In: Croitoru, R (Hrg). The Critical Philosophy and the Function of Cognition. Proceedings of the Fifth International Symposion of the Romanian Kant Society. Bucharest: Diogene, 1995.

KANT, I. Crítica da razão pura. 2. ed. Lisboa: Calouste Gubenkian, 1989.

KANT, I. Kritik der reinen Vernunft. Hamburg: Meiner Verlag, 1998.

KANT, I. Fundamentação da metafísica dos costumes. São Paulo: Abril, 1974. 
KAULBACH, F. Studien zur späten Rechtsphilosophie Kants und ihrer transzendentalen Methode. Würzburg: Königshausen \& Neumann. 1982.

LEBRUN, G. Hobbes aquém do liberalismo. In: LEBRUN, G. A filosofia e sua história. Tradução Marcio Suzuki. São Paulo: Cosac Naify, 2006a, p. 237-252.

LEBRUN, G. Hobbes e a instituição da verdade. In: LEBRUN, G. A filosofia e sua história. Tradução Marcio Suzuki. São Paulo: Cosac Naify, 2006b, p. 297-326.

MARCOS, M. H. La Crítica de la razón pura como proceso civil. Sobre la interpretación jurídica de la filosofía transcendental de I. Kant. Salamanca: Tesis Doctoral, 1994.

MARCOS, M. H. Sobre el carácter jurídico de la razón crítica: logros y perspectivas.

Daimon. Revista de Filosofía, 4. 1992.

MOURA, C. A. R. Hobbes, Locke e a medida do direito. In: MOURA, C. A. R.

Racionalidade e crise: estudos de história da filosofia moderna e contemporânea. São Paulo: Discurso Editorial e Editora da UFPR, 2001. p. 43-63.

PIEVATOLO, M. C. The tribunal of reason: Kant and the juridical nature of pure reason. Ratio Juris, New Jersey, 12, 1999.

PROOPS, I. Kant's legal metaphor and the nature of a deduction. Journal of the History of Philosophy, Baltimore, v. 41. n. 2. 2003.

SEEBERG, U. Kants Vernunftkritik als Gerichtsprozeß. In: BOWMAN, B. (Hg).

Darstellung und Erkenntnis. Paderborn: Mentis Verlag, 2007. p. 61-76.

SEEBERG, U. Ursprung, Umfang und Grenzen der Erkenntnis. Eine Untersuchung zu Kants transzendentaler Deduktion der Kategorien. Hamburg: Philo \& Philo Fine Arts,

SCHMITT, C. The Leviathan in the state theory of Thomas Hobbes. Tradution George Schwab e Erna Hilfstein. Chicago: Chicago University Press, 2008.

STRAUSS, L. Direito natural e história. Tradução Bruno Costa Simões. São Paulo: WMF Martins Fontes, 2014.

STRAUSS, L. The political philosophy of Hobbes. Chicago: Chicago University Press, 1973.

VILLEY, M. A formação do pensamento jurídico moderno. São Paulo: Martins Fontes, 2005. 